\title{
Exercise-induced hypoxemia in an adult patient with an atrial septal defect
}

\author{
Hipoxemia inducida por el ejercicio en una paciente adulta con comunicación \\ interauricular
}

\author{
Carlos E. Vergara-Uzcátegui*, Pablo Salinas, and Luis Nombela-Franco \\ Interventional Cardiology Unit, Hospital Clínico San Carlos. Madrid, Spain
}

Atrial septal defect (ASD) occurs in 1.64 per 1,000 live births and accounts for nearly $10 \%$ of all congenital heart diseases ${ }^{1,2}$. Adults with ASD are almost always asymptomatic or refer mild effort intolerance, although exercise-induced cardiopulmonary function reduction can be demonstrated ${ }^{3}$.

\section{Clinical case}

A 65-year-old woman in whom hypoxemia was detected during preoperative evaluation for scheduled cholecystectomy, after which she was referred to the cardiology department. She had a history of ischemic stroke at 56 years of age. She was on previous follow-up by the pulmonology department since 2001 for hypoxemia, polyglobulia and dyspnea on exertion, with normal spirometry and arterial pressure of oxygen $\left(\mathrm{pO}_{2}\right)$ of $49 \mathrm{mmHg}$. High-resolution chest computed tomography was normal. In 2011, she underwent pulmonary scintigraphy with albumin macro-aggregates consistent with right-to-left shunt being found, but she abandoned follow-up.

Physical examination revealed acropachy, normal lung auscultation, cardiac auscultation with split, and enhanced second sound on pulmonary area. Arterial $\mathrm{pO}_{2}$ of $46 \mathrm{mmHg}$ and $\mathrm{O}_{2}$ saturation of $85 \%$. Laboratory tests showed a hemoglobin level of $16.3 \mathrm{mg} / \mathrm{dL}$ and hematocrit of $50.4 \%$. The electrocargiogram outlined sinus rhythm with signs of biatrial enlargement, left anterior hemiblock and poor R-wave progression in V3-V6.

The transthoracic echocardiogram (TTE) recorded left and right ventricle with normal size and function, mild mitral and tricuspid regurgitation, normal pulmonary artery systolic pressure and aneurysmal interatrial septum (IAS). The left atrium (LA) was normal in size, while the right atrium (RA) was slightly dilated. Transesophageal echocardiogram (TEE) showed IAS aneurysm with $13 \times 8$-mm ostium secundum-type ASD on anterosuperior area (Fig. 1A). Color Doppler described a bidirectional and abundant shunt and early passage of bubbles to left cavities without Valsalva maneuver, which might explain the patient's hypoxemia (Fig. 1B). Cardiac magnetic resonance (Fig. $1 \mathrm{C}$ and D) showed a broad ASD with bidirectional shunt, right ventricle (RV) with normal size and function, and pulmonary veins normal anatomy, running into the $L A$. Blood flow dynamics testing determined a $\mathrm{pQ} / \mathrm{sQ}$ ratio of 0.8 , which suggested predominant right-to-left shunt. No dilatation of the pulmonary artery was observed.

On the 6-minute walk test (6MWT), an initial saturation of $85 \%$ was observed, with a progressive decrease down to $74 \%$ from minute 4 on. After the test, the final saturation at rest was $84 \%$, and the traveled distance was $306 \mathrm{~m}$.

\section{Correspondence:}

${ }^{*}$ Carlos E. Vergara-Uzcátegui

E-mail: carting1@gmail.com
Available online: $20-10-2021$ Arch Cardiol Mex (Eng). 2021;91(3):341-344 www.archivoscardiologia.com 2604-7063 / @ 2021 Instituto Nacional de Cardiología Ignacio Chávez. Published by Permanyer. This is an open access article under the CC BY-NC-ND license (http://creativecommons.org/licenses/by-nc-nd/4.0/). 


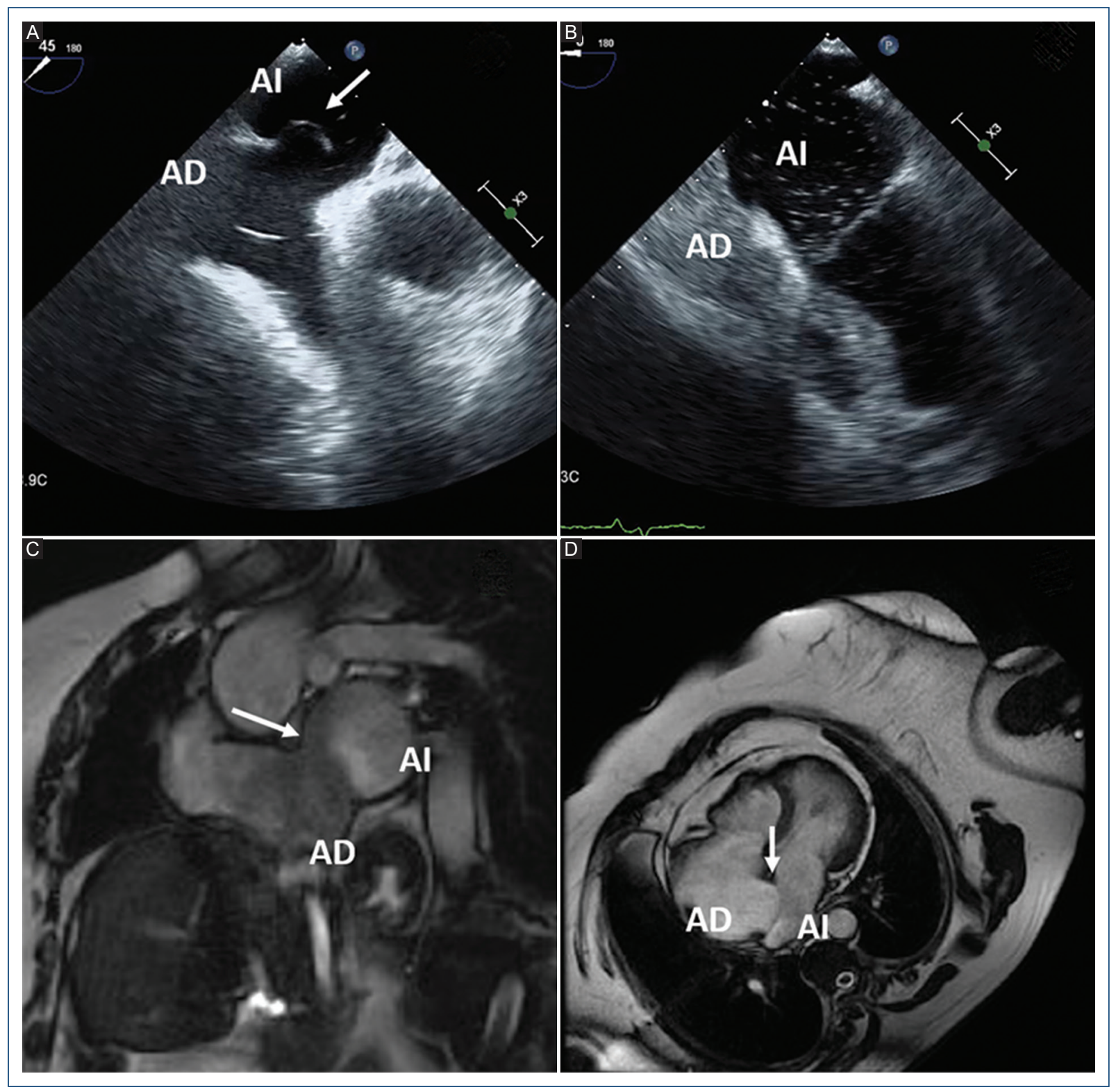

Figure 1. A: Transesophageal echocardiogram at mid-esophageal level at $45^{\circ}$ showing IAS aneurysm (arrow) with ostium secundum-type ASD on anterosuperior area. B: Four-chamber view where early passage of bubbles to left cavities is observed. C: Cardiac magnetic resonance short axis view outlining the passage of contrast towards the LA (arrow). D: Four-chamber view showing aneurysmal IAS (arrow). AD, right atrium; $\mathrm{Al}$, left atrium.

Right catheterization did not reveal significant arterial blood gases oscillation in the right cavities, a sign indicative of neutral or right-to-left shunt, normal pulmonary capillary and right atrial pressure (10 and $8 \mathrm{mmHg}$, respectively). Arterial blood gas test in supine position of $84 \%$ and $90 \%$ in standing position (slight improvement of $6 \%$, which ruled out platypnea-orthodeoxia). ASD percutaneous closure with a 22-mm Amplatzer Septal Occluder device (St.
Jude Medica ${ }^{\circledR}$ ) was uneventfully carried out. $\mathrm{pO}_{2}$ on room air went from 49 to $89 \mathrm{mmHg}$ after the procedure.

On post-closure follow-up, the 6MWT showed 95\% baseline saturation, with a decrease to $92 \%$ at minute 4 and final saturation at rest of $96 \%$. Traveled distance was $405 \mathrm{~m}$. On follow-up 20 months after the procedure, the patient showed an improved functional class (NYHA I) and hemoglobin level of $15.8 \mathrm{~g} / \mathrm{dL}$. On 


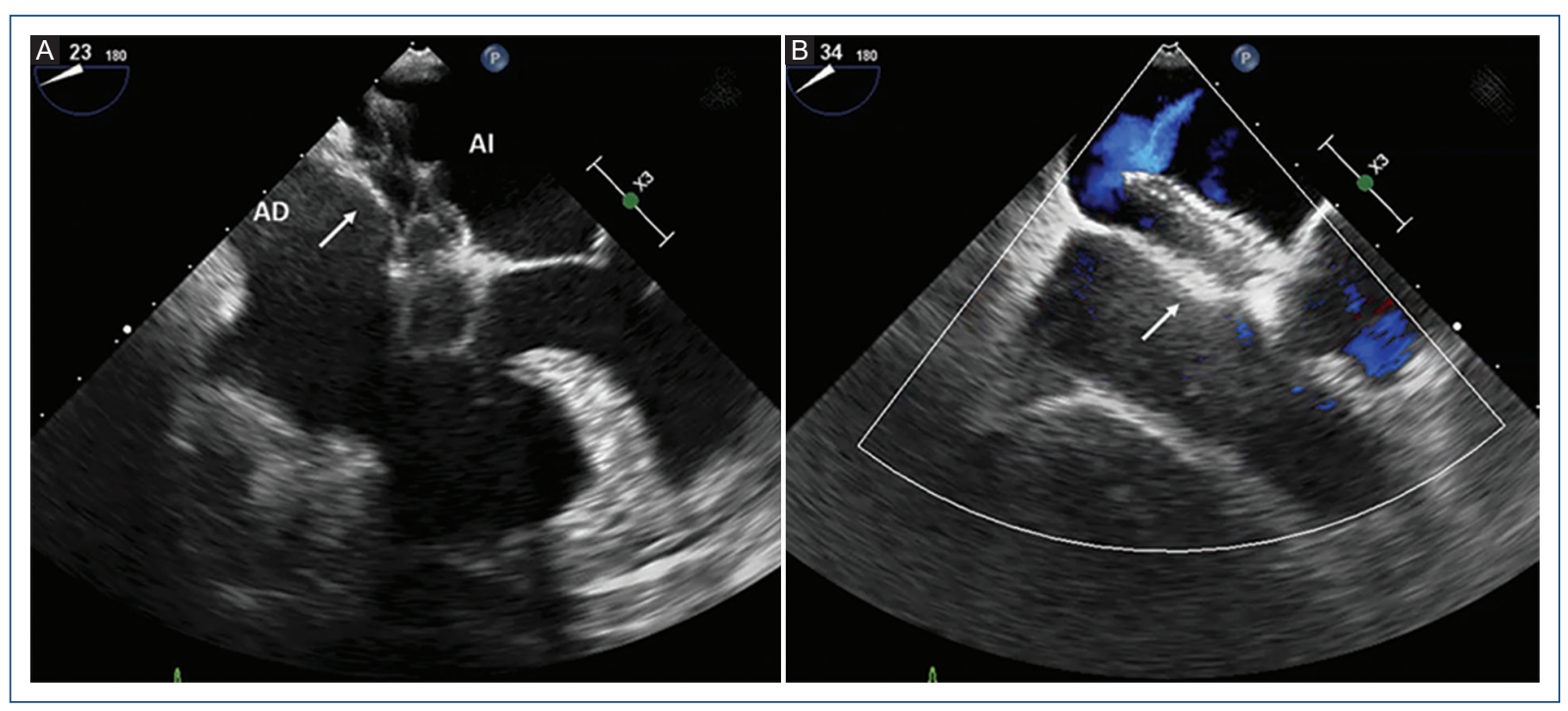

Figure 2. Post-closure transesophageal echocardiogram. A: Four-chamber view. B: Mid-esophageal view at $34^{\circ}$ showing a well-implanted device without residual shunt. $A D$, right atrium; Al, left atrium.

post-closure TEE, a normal IAS-implanted device was observed, without residual shunt (Fig. 2A and B).

\section{Discussion}

Right-to-left shunt across the IAS is a rare cause of exercise-induced hypoxemia ${ }^{4}$. This exercise-induced desaturation would make a right-to-left shunt possible similarly as platypnea-orthodeoxia, but technically different. This desaturation mechanism in the presence of patent foramen ovale (PFO)/ASD can reflect inducible arterial desaturation rather than a permanent shunt, and is a rarely observed phenomenon ${ }^{5}$. Hypoxemia resulting from a rightto-left shunt is common in patients with ASD and elevated pulmonary vascular resistance, but uncommon in the presence of pulmonary hypertension. It is recognized in middle-aged adults with IAS orientation modification.

Two mechanisms have been postulated to explain this hypoxemia: existence of an inter-atrial pressure gradient; and anatomical distortion of the inferior vena cava-IAS spatial relationship and a defect that causes inferior cava vein preferential blood flow towards the $\mathrm{LA}^{6}$. In physiological terms, LA pressure is 5 to $8 \mathrm{mmHg}$ higher than RA pressure ${ }^{5}$. A systolic pressure gradient between RALA has been described in patients with PFO/ASD without pulmonary hypertension in the presence of RA myxomas, RV infarction and mechanical ventilation, particularly in patients with increased positive end-expiratory pressure. This gradient can be exacerbated by postural changes, inspiration, Valsalva maneuvers and RV or RA decreased compliance ${ }^{6}$. Rigorous exercise could increase venous return to a sufficient degree as to generate a pressure gradient and give rise to a transient shunt $^{5}$. At the anatomical level, preferential blood flow streaming from either the superior vena cava or more commonly the inferior vena cava to the LA by way of an over-developed Eustachian valve could also explain the right-to-left shunting phenomenon and occur in the presence of normal right-sided pressures, or in the absence of a pressure gradient between both atria ${ }^{6}$.

In this patient, diagnosis of a cardiac cause that would explain the presence of hypoxemia was delayed because the ASD was not identified in previous TTEs and the patient stopped attending scheduled appointments. The decision to close an ASD of small or moderate size in adults without right cavities' dilatation is controversial; the specific scenario is not foreseen in guidelines and the indication could be considered in case of paradoxical embolism (previous history of stroke in this patient). In the described case, closure was recommended as treatment for hypoxemia after the right-to-left shunt was identified and as prevention for possible paradoxical embolisms.

The 6MWT is a simple and useful clinical tool in functional status assessment; in highly symptomatic patients, correlation with the cardiopulmonary exercise test is 
$\operatorname{good}^{2}$. In this patient, the test was useful and showed an oxygen saturation decrease of up to $11 \%$, with a traveled distance of $306 \mathrm{~m}$ and NYHA functional class III.

Contrast echocardiography is useful to rule out, in cases like this, IAS defects ${ }^{4}$. TEE can show the rightto-left shunt in a PFO or ASD by color Doppler or after contrast intravenous injection ${ }^{6}$, and can also evaluate anatomical distortions, such as a prominent Eustachian valve or septal deviation by aortic dilatation.

In well-selected cases, closure of the defect leads to arterial desaturation resolution and improves functional capacity in patients with exercise-induced desaturation $^{5}$. In case of doubt, a balloon occlusion test of the defect can be performed, although it should be borne in mind that the anatomical position at the hemodynamics room might not be representative of desaturation on a supine plane in cases of platypnea-orthodeoxia. In this patient, percutaneous closure was successfully performed and with immediate saturation improvement, and during follow-up visits, an improvement in functional capacity, absence of considerable desaturation on $6 \mathrm{MWT}$ and a $32 \%$ increase in travelled distance were observed. Although functional class evaluation can be subjective, arterial desaturation improvement appears to be a common phenomenon in treated patients ${ }^{5}$.

\section{Funding}

This research has not received specific support from public or commercial sector agencies, or non-profit entities.

\section{Conflicts of interest}

Luis Nombela-Franco is proctor at Abbott Medical. There are no other conflicts of interest.

\section{Ethical disclosures}

Protection of human and animal subjects. The authors declare that no experiments were performed on humans or animals for this research.

Confidentiality of data. The authors declare they have followed the protocols of their work center on the publication of patient data.

Right to privacy and informed consent. The authors have obtained informed consent from the patients or subjects referred to in the article. This document is in the possession of the corresponding author.

\section{References}

1. Supomo S, Darmawan $H$, Arjana AZ. Role of pulmonary hemodynamics in determining 6-minute walk test result in atrial septal defect: an observational study. J Cardiothorac Surg. 2018;13:51.

2. Wang, S, Pan, J, Xiao, B. Immediate and shortterm effects of transcatheter device closure of large atrial septal defect in senior people. Congenital Heart Disease. 2019;14:939-44.

3. Khan AA, Tan JL, Li W. The impact of transcatheter atrial septal defect closure in the older population. J Am Coll Cardiol Intv. 2010;3:276-81.

4. Eckersley L, Clements B, Shipton S. Exercise-induced hypoxia secondary to an atrial septal defect and cor triatriatum dexter. Cardiology in the Young. 2016;26:793-5.

5. Devendra GP, Rane AA, Krasuski RA. Provoked exercise desaturation in patent foramen ovale and impact of percutaneous closure. J Am Coll Cardiol Intv. 2012;5:416-9.

6. Godart F, Rey C, Prat A. Atrial right-to-left shunting causing severe hypoxaemia despite normal right-sided pressures. Report of 11 consecutive cases corrected by percutaneous closure. Eur Heart J. 2000; 21:483-9. 